\section{PENELITIAN PENGGUNAAN RESIN EPOKSI UNTUK MEMBUAT LANDASAN POTONG PON}

Oleh : Dwi Wahini Nurhajati, Pramono, Supriyanto B, Supriyadi

\section{ABSTRACT}

Application of epoxy resin to make specimen punching pad was studied. The specimen punch ing pad compound was made from epoxy resin, $\mathrm{CaCO}_{3}$ as filler, colour paste, and hardener. The compound was moulded in to specimen punching and moulding by casting moulding during 24 hours. Physical test result of the compound saw that compound which it consist of epoxy resin : 100 parts, $\mathrm{CaCO}_{3}: 20$ parts, hardener : 100 parts, colour paste : 1 required, has physical property like the physical property of the imported specimen punching pad Presence of $\mathrm{CaCO}$, as filler caused the specimen punching pad surface which it punched by cutter became brittle.

\section{INTISARI}

Telah dilakukan penelitian tentang penggunaan resin epoksi untuk membuat landasan potong pon. Kompon landasan potong pon dibuat dari resin epoksi, $\mathrm{CaCO}$ sebagai filler, pewarna dan hardener. Kompon dicetak dalam cetakan landasan potong pon menggunakan sistim tuang dengan waktu pencetakan selama 24 jam. Hasil uji sifat fisis menunjukkan bahwa kompon yang berisi resin epoksi : 100 bagian, pewarna : sesuai kebutuhan, mempunyai sifa fisis yang menyerupai sifat fisis landasan potong pon impor. Adanya $\mathrm{CaCO}_{3}$ sebagai filler menyebabkan permukaan landasan potong pon yang terkena pisau potong menjadi rapuh.

\section{PENDAHULUAN}

Landasan potong pon yang banyak digunakan di pabrik sepatu merupakan produk impor dan dibuat dari resin jenis termoplastik. Untuk membantu menyediakan kabutuhan landasan potong pon bagi pabrik sepatu maka telah dicoba membuat landasan potong pon dari resin epoksi yang merupakan resin jenis termoset dengan teknologi cetak tuang

Resin epoksi pada umumnya sebagai hasil reaksi antara Bisfenol A dengan Epoklorhidrin. Resin ini bersifat anti karat, kuat, tingkat penyusutan kecil, perekatan baik dan tahan terhadap kondisi lingkungan. Penggunaan terbanyak dari resin ini adalah untuk perekat pada bahan-bahan logam, gelas, keramik, kayu, beton maupun plastik (1). Untuk merubah resin epoksi yang tadinya lembek tidak mudah kering menjadi keras, licin dan tahan korosi, maka resin epoksi ini dicampur dengan hardener sampai homogen (3).

Mengingat resin epoksi merupakan resin yang lembek maka perlu ditambahkan bahan pengisi agar dapat dicetak menjadi landasan potong pon dengan

Majalah Barang Kulit, Karet dan Plastik ukuran yang dikehendaki.

Pencetakan resin epoksi lebih banyak dikerjakan pada suhu kamar yaitu dengan tambahan hardener yang anti karat, menggunakan cetakan terbuka (2).

Berbagai filler dapat ditambahkan untuk memperbaiki ketahanan pukul, ketahanan panas dan ketahanan gesekan. Pada penelitian ini digunakan bahan pengisi $\mathrm{CaCO}_{1}$

\section{MATERI DAN METODE PENELITIAN}

1. Materi Penelitian

1.1 Bahan

Bahan-bahan yang digunakan dalam penelitian ini adalah resin epoksi, hardener, filler $\mathrm{CaCO}_{3}$, dan pewarna.

1.2 Peralatan

Peralatan yang digunakan berupa cetakan landasan potong pon yang berbentuk empat persegi panjang, timbangan listrik, alat uji kekerasan (Shore B Durometer), dan alat uji ketahanan pukul.

\section{Metode Penelitian}

2.1 Proses Pembuatan kompon

Proses pembuatan kompon dilakukan sebagai berikut :

Resin epoksi dicampur dengan filler $\mathrm{CaCO}_{3}$ yang jumlahnya bervariasi (lihat tabel 1.) aduk hingga homogen. Selanjutnya campuran tersebut diberi pewarna yang diinginkan lalu dicampur dengan hardener dan aduk hingga homogen. Perbandingan resin epoksi dengan hardenernya adalah $1: 1$.

Tabel 1. Formula kompon Landasan Potong Pon.

\begin{tabular}{|c|c|c|c|}
\hline Formula & Resin Epoksi (bag) & Hardener (bag) & $\mathrm{CaCO}_{3}$ \\
\hline I & 100 & 100 & 10 \\
II & 100 & 100 & 20 \\
III & 100 & 100 & 30 \\
IV & 100 & 100 & 40 \\
V & 100 & 100 & 50 \\
\hline
\end{tabular}

\subsection{Proses Pencetakan}

Kompon epoksi dicetak menjadi landasan potong pon menggunakan sistim

Vol. XII No, 24 Th. 1996/1997 
cetak tuang pada suhu kamar dengan cetakan terbuka. Selanjutnya dibiarkan selama 24 jam agar terjadi proses curing.

\subsection{Pengujian}

Kompon landasan potong yang dibuat dengan formula seperti pada tabel 1 , diuji sifat kekerasannya dan ketahanan pukulnya. Formula yang menunjuk-kan hasil uji yang terbaik selanjutnya dicetak menjadi landasan potong pon dan diuji coba untuk digunakan di pabrik pengguna.

\section{HASIL PENELITIAN DAN PEMBAHASAN}

Hasil uji kekerasan dan ketahanan pukul kompon landasan potong pon dapat dilihat pada tabel 2.

Tabel 2. Hasil uji kekerasan dan ketahanan pukul kompon landasan potong pon.

\begin{tabular}{|c|c|l|}
\hline Formula & Kekerasan Shore D & Ketahanan Pukul \\
\hline 1. & 78,4 & $10 \mathrm{x}$ ulangan tidak pecah \\
2. & 78,6 & $10 \mathrm{x}$ ulangan tidak pecah \\
3. & 81,0 & $3 \mathrm{x}$ ulangan pecah \\
4. & 81,2 & $1 \mathrm{x}$ ulangan pecah \\
5. & 81,6 & $1 \mathrm{x}$ ulangan pecah \\
kontrol & 75 & $10 \mathrm{x}$ ulangan pecah \\
\hline
\end{tabular}

Kompon formula 1 dengan kandungan bahan pengisi $\mathrm{CaCO}_{3}$ sebanyak 10 bagian mempunyai kekerasan 78,4 Shore D tidak pecah setelah diuji ketahanan pukulnya sebanyak $10 \mathrm{x}$ ulangan. Demikian juga untuk kompon formula 2 dengan kandungan $\mathrm{CaCO}_{3} 20$ bagian yang mempunyai kekerasan 78,6 Shore D, tidak pecah setelah diuji ketahanan pukulnya sampai 10 kali ulangan. Kompon formula 3 mempunyai kandungan $\mathrm{CaCO}_{3}: 30$ bagian, kekerasannya 81,0 Shore $\mathrm{D}$, pecah setelah diuji ketahanan pukul sebanyak 3 kali ulangan, kompon formula 4 dengan kandungan $\mathrm{CaCO}_{3} 40$ bagian dan kompon formula 5 yang mempunyai kandungan $\mathrm{CaCO}_{3} 50$ bagian, pecah pada waktu diuji ketahanan pukulnya sebanyak 1 kali ulangan. Sebagai kontrol adalah landasan potong pon impor yang mempunyai kekerasan 75 Shore D, dan tidak pecah setelah diuji ketahanan pukulnya sebanyak 10 kali ulangan.

Dari tabel 2 terlihat bahwa semakin banyak kandungan bahan pengisi yang berupa $\mathrm{CaCO}_{3}$, kekerasannya semakin tinggi, tetapi menyebabkan kompon getas dan tidak tahan pukul.
Mengingat sifat fisis kompon formula 1 dan formula 2 tidak jauh berbeda (lihat tabel 2), sedang ditinjau dari segi ekonomi formula 2 yang mempunya kandungan bahan pengisi lebih banyak dari pada formula 1 tentunya lebih ekonomis, maka kompon formula 2 yang dicetak menjadi landasan potong pon dengan ukuran $80 \mathrm{~cm} \times 50 \mathrm{~cm} \times 4 \mathrm{~cm}$ dan selanjutnya diuji coba digunakan di pabrik pengguna.

Hasil uji coba penggunaan landasan potong pon hasil penelitian dan landasan potong pon impor, di pabrik pengguna (pabrik sepatu) dapat dilihat pada tabel 3 .

Tabel 3. Hasil uji coba penggunaan landasan potong pon di pabrik sepatu

\begin{tabular}{|c|c|c|}
\hline & Landasan Potong Pon Hasil Penelitian & Landasan Potong Pon Impor \\
\hline 1. & Permukaan keras & 1. Permukaan keras dan liat \\
\hline 2. & Bekas pisau potong tidak merapat kembali & 2. Bekas pisau potong tidak merapat kembali \\
\hline 3. & $\begin{array}{l}\text { Permukaan yang terkena pisau potong } \\
\text { terlihat rapuh }\end{array}$ & $\begin{array}{l}\text { 3. Permukaan yang terkena pisau potong } \\
\text { terlihat tidak rapuh }\end{array}$ \\
\hline 4. & Hasil potongan rata/rapih & 4. Hasil potongan kurang rapih \\
\hline
\end{tabular}

Dibandingkan dengan landasan potong pon impor, maka permukaan landasan potong pon hasil penelitian yang terkena pisau potong terlihat rapuh, hal ini kemungkinan karena digunakannya $\mathrm{CaCO}_{3}$ sebagai bahan pengisi mengingat resin epoksi sendiri bersifat liat. Hasil potongan yang menggunakan landasan potong pon hasil penelitian terlihat lebih rapih dibandingkan yang menggunakan landasan potong pon impor.

\section{KESIMPULAN}

Kesimpulan yang dapat diambil dari hasil penelitian penggunaan resin epoksi untuk membuat landasan potong pon adalah :

1. Resin epoksi dapat dicetak menjadi landasan potong pon yang sifat fisisnya mendekati landasan potong pon impor, menggunakan sistim tuang dengan waktu pencetakan 24 jam.

2. Formula kompon landasan potong pon yang sifat fisisnya mendekati landasan potong pon impor yaitu kompon yang berisi :

$\begin{array}{llrl}\text { - resin epoksi } & : & 100 & \text { bagian } \\ \text { - hardener } & : & 100 & \text { bagian } \\ \text { - filler } \mathrm{CaCO}_{3} & : & 20 & \text { bagian }\end{array}$

- pewarna : secukupnya

3. Penggunaan $\mathrm{CaCO}_{3}$ sebagai filler menyebabkan permukaan landasan potong pon yang terkena pisau potong terlihat rapuh. 
4. Hasil potongan kulit yang menggunakan landasan potong pon hasil penelitian terlihat lebih rapih dibandingkan yang menggunakan landasan potong pon impor.

\section{DAFTAR PUSTAKA}

1. Brydson, JA, Plastics Materials, Fourth Edition, Polytechnics of North London, 1982.

2. Joel Frados, Plastics Engineering Handbook, Society of The Plastics Industry, Inc, Van Nostrand Reinhold Company, 1976.

3. Rachmat Supardi, H, Drs, Metal Indonesia, Vol. 015/1993, Hal 36-38, (1993), 